\title{
El Camp y otras ciudades. Una Ciudad-Territorio reflejada en otras similares
}

\author{
Jordi Sardà Ferran', Federica Greco², \\ Panita Karamanea $^{3}$, Lluís Delclòs Alió ${ }^{4}$
}

${ }^{14}$ Centre de Recerca Urbana del Camp (CRUC). Unidad Predepartamental de Arquitectura. Escuela Técnica Superior de Arquitectura. Universitat Rovira i Virgili. Reus, Tarragona, España, ${ }^{2}$ Regione Puglia, Dipartamento di Mobilità Qualità Urbana, Opere Pubbliche, Ecologia e Paesaggio, Bari, Italia ${ }^{3}$ Scholí Architektónon Michanikón, Polytechneio Kritis, Chania, Grecia E-mail: 1jordi.sardaf@urv.cat, ${ }^{2}$ federica.greco@regione.puglia.it, 3panit27@hotmail.com, ${ }^{4}$ lluis.delclos@gmail.com

\begin{abstract}
Resumen. Eulesis, Taranto y el Camp (Camp de Tarragona) nos presentan tres modelos de ciudad Industrial diferentes, en posición, disposición y medida. Situadas en posiciones territoriales distintas, Eulesis es periferia de Atenas, el Camp está ya a $100 \mathrm{~km}$ de la metrópolis Barcelona y Taranto no tiene competencia. Las tres comparten una urbanidad antigua con una industrialización súbita y desmesurada sólo explicable por las condiciones posicionales y fisicas de sus territorios: accesibilidad por mar y suelo disponible. En las tres, la industria ha cambiado su sentido y destino. Todas las industrias descritas: refinerías de petróleo, centrales nucleares, acererías, arsenales... son exógenas y con seguridad caducas, pero hoy por hoy tienen contrato indefinido.

Taranto y su fábrica son casi iguales de medida y una es saprofita de la otra. Es el caso de conflicto más directo y claro. Eulesis es un verdadero palimpsesto de historia e industria que impide cualquier otro uso del suelo, la idea de zoning ya no tiene ahi sentido. En el Camp el turismo masivo-quizá nocivo- parece querer ser un nuevo agente y factor de equilibrio a tal fin ha establecido límites $y$ equilibrios interesantes y quizá paradigmáticos. Sólo hemos detectado los casos de estudio. Creemos que por sus similitudes, genéricas y su diversidad implícita, son oportunos. Empieza ahora la comparación verdadera.
\end{abstract}

Palabras clave: El Camp, Camp de Tarragona, Taranto, Eleusis,

Ciudad-territorio, Ciudad de ciudades, conflicto industria y turismo.

"Quell'angolo di mondo più d'ogni altro m'allieta, là dove $i$ mieli a gara con quelli del monte Imetto fanno e le olive quelle della virente Venafro eguagliano; dove Giove primavere regala, lunghe, e tiepidi inverni, e dove Aulone, caro pure a Bacco che tutto feconda, il liquor d'uva dei vitigni di Falerno non invidia affatto."

(Quinto Orazio Flacco, Ode a Settimio, traduzione di Enrico Vetrò in Galeso, Novecento metri di mito, 2005, II, 6, 10)

\section{Presentación}

Tony Garnier, arquitecto formado en l'École des Beaux Arts de Lyon (1886) y en la de París (1890) llevó a Roma, para desarrollar su "Gran Prix", un tema novedoso y extraño: "La Citté Industrielle" (Garnier, 1917 - 32). Ganó la convocatoria de 1899 y concluyó su beca en 1904 con una propuesta para una ciudad de 36.000 habitantes ubicada "idealmente" entre Givors y Saint Etienne, en las riberas del Gier, un lugar que, de hecho, era ya y aún es, una específica y continua ciudad industrial. 
En ilustraciones magníficas, Garnier dibujaba una nueva ciudad industrial con la actividad industrial en el centro del debate y la voluntad utópica de la armonía social en la base de una novedosa organización urbana.

Estableció Garnier que además del trabajo y la energía, las claves de su ciudad sería la relación entre las piezas: centro direccional, zona residencial, estación, hospital, zona industrial, presa hidroeléctrica. A través de un sistema de movilidad - tren, tranvía, transporte fluvial - perfectamente establecido que relacionaba un puzle que nunca encajaba del todo. El vacío, verde y natural, separaba y envolvía cada una de las piezas, protegiéndolas y evitando inoportunos encuentros. Sin querer, había establecido la teoría soporte del "zoning" y de la Carta de Atenas.

Pero Garnier fue un socialista-utópico y no paró de reformar y mejorar su propuesta de Ciudad Ideal. Imaginamos que el proyecto elaborado en los años de Roma, acompañó y "vigiló" - desde la mesa vecina- los diseños de los grandes y magníficos proyectos de equipamientos: les abattoirs de la Mouche -1906-1928- y el Hospital Edouard Herriot -1913-33- y de vivienda social: quartier des États Unis -1917-34- construidos en el ensanche del Gran Lyon. El 1914, el conjunto de los abattoirs, aún por terminar, acogió la exposición International Urbaine "la Cité Moderne". Tony Garnier fue arquitecto municipal de Lyon desde 1905, pero la publicación de la Cité Industrielle no vio la luz hasta 1917. La segunda edición revisada es de 1932.

Los valles franceses, ingleses o alemanes han ido cerrando, minas y metalurgias y la industria del carbón y del acero ha dejado paso a la del petróleo y la energía nuclear. Por este motivo las nuevas ciudades industriales a menudo se han trasladado a los litorales marítimos, buscando puertos aptos para los grandes buques y aguas capaces de refrigerar centrales nucleares, alterando así profundamente la escala de la costa y sus ciudades, a menudo territorios y ciudades de gran valor histórico, sobre los que sustentará la nueva actividad. A la vez este fenómeno ha coincidido, en tiempo y espacio, con otro de enorme trascendencia: el turismo. En efecto en la segunda mitad del s. XX las clases medias del centro de Europa, rehechas de la sangría de las dos grandes guerras, con: tiempo, vacaciones pagadas, movilidad y algo de dinero, se han acercado al Mediterráneo y a sus playas en busca de los supuestos beneficios de los baños de mar. El conflicto está servido. Gran industria y producción de energía versus ocio y turismo de sol y playa. Conviviendo en el mismo marco de territorios fértiles y de ciudades históricas, a menudo de enorme riqueza agrícola e indiscutible valor patrimonial. Han construido un nuevo y continuo palimpsesto que, de la mano de André Corboz (Corboz, 2001), aprenderemos a descifrar y a querer. Garnier imaginó seguro otro tipo de conflicto, y de Ciudad Ideal.

\section{Los casos de estudio}

\section{Eleusis}

Eleusis ha estado poblada desde el año 2800 a. C., y desde el 1600 hasta el 400 fue una de las cinco ciudades sagradas de la Grecia antigua. Desde el fin del s.VIII a. C. el templo sagrado de la diosa Deméter y su hija Perséfone y los misterios sagrados eleusinos, donde pocos se iniciaban y que Platón describe, le han dado una fama diacrónica en todo el mundo antiguo. Aquí llegaba la procesión sagrada desde Iera Odos -calle sagrada- cada otoño y aquí en el s.VI a. C. nació el poeta trágico Esquilo.

El golfo de Eleusina se ubica en el litoral noroeste de la Ática. Es un golfo semicerrado. El territorio se denomina Thriasion Pedion y forma un gran valle rodeado por 3 montañas y abierto por el sur al mar, cerrado por la isla de Salamina. Tiene una profundidad de $9 \mathrm{~km}$ por el norte y un litoral de $16 \mathrm{~km}$. Tiene una superficie de, aproximadamente, 10.000 ha que, durante los últimos 20 años, se ha urbanizado totalmente. Sólo la barrera geográfica de la montaña, en el este, lo separa de Atenas. Desde la antigüedad la zona estuvo cubierta por olivos, hasta que a finales del s. XIX (1875-1906), al ser costera, contar ferrocarril y estando a tan sólo a $20 \mathrm{~km}$ del centro de la capital, atrajo el interés industrial.

Durante el período de entreguerras (19231939) y especialmente desde mitades del siglo XX (1948-1980) la industria tuvo un 
gran auge. Como resultado, un ámbito de 250ha se declaró, por ley, zona industrial. Las industrias fueron, al principio, bodegas de producción de aceite y jabón, pinturas y de cerámicas. En los años siguientes aparecieron las industrias petroquímicas, las siderúrgicas, los astilleros navales, la industria cementera y la refinería de petróleo, la terminal de mercancías ferroviarias, los almacenes y sus logísticas. Hoy día, Thriasion Pedion es uno de los mayores centros industriales y de gestión del país, y no para de aumentar. Ya desde sus inicios, en el siglo XIX, la primera industria se ubicó justo al lado del yacimiento arqueológico del Templo de los Sagrados Eleusinos, creando una contradicción espacial y conceptual en el lugar que, obviamente, está aún presente. (Belavilas et al, 2011)

Los cuatro asentamientos que contiene (Eleusina, Magula, Mandra, Aspropirgos) tienen 78.200 habitantes (2011) de los cuales el $65 \%$ trabaja en la industria. Las formas urbanas configuran una entidad continua, difusa y unificada donde se intercalan las zonas industriales. Hace falta destacar que, de los $15 \mathrm{~km}$ del litoral, $12 \mathrm{~km}$ son de zona industrial que impide la expansión urbana o turística a lo largo del mar. Simultáneamente a toda la presión industrial, la polución medioambiental provocada es innegable.

La municipalidad está siendo muy activa, busca alternativas para recuperar espacios -metafóricamente y literalmente- para la sociedad, apostando mucho por la cultura y el arte. La ciudad de Eleusina será Capital Cultural de Europa el año 2021 y tiene un plan de colaboraciones culturales -Programa cultura 2030-. Cada año organiza un festival teatral amparado en Esquilo; intenta involucrar a sus ciudadanos en iniciativas de diseño colaborativo y ha organizado un programa de relación de los sitios arqueológicos y las industrias inactivas del territorio, dirigido por el Ministerio de Obras Públicas.

Entre las industrias, que están funcionando y se renuevan sin parar, todavía se encuentran edificios antiguos de un gran interés arquitectónico y arqueológico (Galanis, 2016). A su vez conviven con "monumentos" industriales en buenas condiciones que pueden ser restaurados creando un parque industrial de memoria cultural. Toda la zona tiene un gran valor arqueológico y simbólico para el imaginario común, combinado con un pasado industrial muy intenso. Quizás Eleusis podría ser un ejemplo piloto de modelo híbrido: de herencia industrial con importancia histórica y arqueológica, un polo cultural potente con un litoral todavía por recuperar, con muchas industrias cerradas allí localizadas.

La zona, además, está en alto peligro de inundación dado que en el año 2017 sufrió de una gran catástrofe medioambiental en la que, a causa de las lluvias, se ahogaron 15 personas. Es crucial e imperativo redibujar el territorio con zonas de tránsito, incorporando parámetros paisajísticos y medioambientales, manteniendo la memoria del lugar y manejando la presión del desarrollo. Para ello se podría considerar Eleusina a la vez como un recurso industrial - arqueológico - cultural bajo un paraguas medioambiental. Eleusis es un palimpsesto manuscrito con una sociedad muy activa, un lugar de patrimonio europeo que posee posibilidades fértiles de formar un modelo de ciudad industrial sostenible, de acuerdo con su paisaje. Una ciudad de sinergias.

Eleusina y Thriasion Pedion constituyen una formación territorial en crisis y quizás dentro de sus contradicciones y paradojas se encuentra la solución. Seguramente, la apuesta urbanística pase por repensar la identidad de este territorio histórico y establecer una estrategia simbiótica que organice las zonas industriales y de desindustrialización, que restaure la estructura urbana y sus usos, afrontando a la vez los problemas socioeconómicos. A través de la memoria histórica, el capital arqueológicoindustrial y la renovación del litoral, quizás se puede recuperar el perfil contemporáneo a una ciudad industrial del siglo XXI para que saque partido de su condición y del conflicto

\section{Taranto}

La Provincia de Taranto, establecida en 1923, es una de las seis de la región Puglia. Incluye 29 municipios con un área total de 2,467.35 $\mathrm{km} 2$ y 586,061 habitantes (2016). El municipio de Taranto tiene un área de 249.86 kilómetros cuadrados y una población de 199,561 (2018) habitantes. La posición de la ciudad, -en un 
gran golfo natural- ha representado desde su fundación, una fortaleza y al mismo tiempo una debilidad. La isla -Borgo Antico- es el núcleo original de la ciudad. El Borgo Nuovo -llamado Umbertino- comenzó a desarrollarse entre 1865 y 1883 . La "ciudad de los dos mares" (Mare Piccolo y Mare Grande) fue elegida como base de la flota naval durante la Primera Guerra Mundial. En la segunda, la Royal Air Force, destruyo, en una noche, la Regia Marina, concentrada en Taranto.

En 1960, llega a Taranto, gracias a la decisión de ubicar en su territorio el centro de acerería Italsider, ahora Ilva (Romeo, 2019), un nuevo impulso económico. Eso incrementó la población hasta los 244.000 habitantes, en 1981, pero desde los años 90 ha habido una disminución dramática de sus residentes. La autonomía administrativa de Statte, con sus 10.000 habitantes obtenida en 1993, fue acompañada de la crisis en la industria del hierro y del acero y de la posterior privatización de la acerería, con los consiguientes recortes de empleo. Estos factores, en una ciudad industrial con una suerte de monocultivo y en ausencia de alternativas de producción creíbles, determinaron una huida forzada hacia lugares donde se esperaba encontrar una ocupación mejor y más estable.

Aún en la actualidad, el área industrial ocupa el doble de la superficie de la ciudad equivalente a 1500 hectáreas - y a dos tercios del puerto comercial, lo que indica su impacto territorial y urbano. Pero el reconocimiento oficial de la dramática situación ambiental tiene lugar el 30 de noviembre de 1990, con la deliberación del Consejo de Ministros que declara el territorio de la provincia de Taranto "Área con alto riesgo de crisis ambiental".

La ciudad ha buscado y recibido fondos europeos, estatales y regionales, aunque estos recursos nunca han sido utilizados de manera efectiva. Por lo que se refiere al turismo -que se desarrolló a partir de la posguerra-, es principalmente de carácter local y tan solo se activa unos pocos meses al año a lo largo de la costa sur de la ciudad. Ni la agricultura, una vez fuente de prosperidad económica para la ciudad, ni el turismo no representan, en este momento, alternativas válidas para el crecimiento económico de la ciudad y no pueden compensar la fortaleza de la presencia industrial.

La importancia de Taranto en relación con los complejos problemas relacionados con la gestión de la ciudad ha llevado a la región de Puglia a aprobar una ley regional (L.R. n.2 de 25-01-2018 Indirizzi per lo sviluppo, la sostenibilità ambientale e la coesione economica e sociale del territorio di Taranto). La ley establece que la Región tiene que adoptar un plan estratégico llamado "Taranto Futuro Prossimo". En la primera fase de estudio del territorio de Taranto se han reconocido 138 proyectos y 28 organismos públicos para su ejecución. Son muchos, quizá demasiados.

Lo que sugiere y confirma este breve cuadro descriptivo es que los eventos que caracterizan la historia de Taranto están vinculados a decisiones no tomadas directamente desde la ciudad, pero a menudo son "sufridas" por los actores locales. A pesar de todo, el puerto de Taranto posee una posición estratégica con respecto a las principales rutas entre el Este y el Oeste y representa un punto fuerte de la ciudad, junto con la densa red de infraestructura del "cielo", Aeropuerto de Grottaglie; del "hierro", ferrocarriles de Estado y locales; y de "tierra", final de la autopista A14, que confieren al territorio de Taranto (Greco et al., 2017) una posición privilegiada.

En efecto, Taranto posee un gran potencial desde el punto de vista geográfico y de dotación de recursos naturales: la antigua zona pantanosa La Vela, de aproximadamente 242 hectáreas; la desembocadura de rios y torrentes, como el Galese, Tara...; la antigua fuente de Battendieri; los paisajes de recuperación hidráulica o los bordes del antiguo bosque de pinos de alepo a lo largo del Mar Piccolo. Estos factores enmarcan un patrimonio histórico y arqueológico excepcional presente en el museo arqueológico MArTA y también arquitectónico, visible en los notables edificios de la época fascista en el paseo Vittorio Emanuele. Dicho esto, la ciudad se ha caracterizado por un comportamiento contradictorio e inadecuado, tanto de la comunidad local como de sus administraciones, para salvaguardar y mejorar el extraordinario patrimonio descrito y hacerlo motor de estima y cambio (Camarada et al, 2015) (Sardà et al., 2014). 
Quizás, Taranto tiene que redescubrir que es una "ciudad mediterránea del agua". (Lenoci, 2005) (Luisi et al., 2019)

\section{El Camp}

El Camp de Tarragona, es el territorio formado por les comarcas naturales: Alt Camp, Baix Camp i Tarragonès (Iglésies, 1958). Son las comarcas establecidas en la Delimitación Territorial de Catalunya de 1936 (Vila, 1936), división comarcal restaurada por el Estatut d'Autonomia de Catalunya de 2006, lo constituyen 73 municipios dispuestos) en un territorio de $1545 \mathrm{~km} 2$ con una población de 485.790 habitantes (2014) acumulados especialmente en las ciudades capitales: Tarragona, Reus, Valls y en los municipios costeros: Altafulla, Cambrils, Salou, Torredembarra y Vila-seca.

El territorio posee un relieve casi plano -especialmente la mitad sur- y una forma casi triangular, abierta al mar por su lado mayor. Está protegido por las Sierras prelitorales centrales: Llaberia, Montsant, Mussara, Ancosa y Muntanyes de Prades que alcanzan su mayor altitud -1202m- en el Tossal de la Balatasana. Está drenado por dos ríos: el Gaià -de $57 \mathrm{~km}$ de longitud y $424 \mathrm{~km}$ de cuenca- y el Francolí - $60 \mathrm{~km}$ de longitud y 838 $\mathrm{km}$ de cuenca- y por numerosas rieras, aún más cortas, todas de régimen estacional. Los asentamientos neolíticos y las ciudades ibéricas son abundantes en el Camp pero menos que en el Valle del Ebro. La fundación de Tarraco sobre Tarrakon, el 217 a.C.- como base de operaciones de las guerras púnicas primero y como puerto estratégico y capital de una extensa provincia luego, supone la vinculación de todo el Camp a la cultura romana.

Disuelto el Imperio, la Ciudad: Tarraco y el Camp se convertirán en tierra de nadie, entre los condados cristianos del norte: Urgell, Barcelona y Tortosa al sur -control del paso del Ebro-. Ramon Berenguer III donó El Camp al arzobispo de Tarragona, recién restituido y el nuevo territorio se refundó a través de la implantación de franquicias religiosas leales al rey. Santes Creus -es fundado en 1170 - en las riberas del río Gaià, por monjes cistercienses de Tolosa de Llenguadoc. Poblet lo había sido ya en la cabecera del Francolí en 1151. Esta situación confirmaría el Camp como un territorio regido por el poder religioso, pero los nuevos y abundantes municipios, constituidos en Comuna del Camp (Morera i Llauradó, 1901) desde 1336, significarán su voluntad de contrapoder civil.

El crecimiento demográfico del Camp lo es especialmente de sus ciudades mercado: Reus y Valls, pero no se produce hasta la segunda mitad del s. XVIII, gracias al éxito de las exportaciones de alcohol. Los capitales acumulados financiarán la industrialización: de derivados agrícolas y del textil. En 1857 (6) las tres ciudades del Camp figuraban entre las diez más pobladas de Catalunya -Reus es la segunda, con 28.171 habitantes detrás de Barcelona-. Nunca más volverá a ser así, pero la vocación industrial del Camp perdura hasta hoy. Y aunque las industrias del s. XIX usaban los recursos -a veces exignos - del propio territorio: agua para los curtidos de Valls o productos agrícolas: vino y trigo en Reus, algunos son elaborados ya claramente con materias primas exógenas: las bases de las textiles, seda o lana, siempre se importan.

El primer tren: -Reus-Puerto de Tarragonaes de 1851, posteriormente la línea ValenciaBarcelona alcanza Tarragona, desde el sur, en 1865. En 1879 se completa la línea ReusLleida y en 1884 se pone en marcha la línea de "los directos" de Madrid a Barcelona con estación en Reus. Hasta la llegada del AVE (2006) la estructura ferroviaria del Camp estará concluida, pero la vía Amalia: Reus-Tarragona es anterior de 1827.

La primera autopista de España: MongatMataró es de 1969, y no llega al Camp desde Martorell- hasta 15 años después, pero hoy la recorre -en paralelo a la costa- en toda su longitud y la conecta con la movilidad europea. El turismo, primero incipiente, luego masivo, entrará fácilmente por ella. También lo hará por el Aeropuerto de Reus: un aeroclub abierto desde 1957 al tráfico regular, pero que no alcanza hasta 2004 -con vuelos chárter- el millón de pasajeros. El corredor del Mediterráneo -acabado- espera inauguración. A partir de este momento el Camp, poseerá el nudo ferroviario - de alta velocidad- de mayor envergadura del estado después de Madrid. 

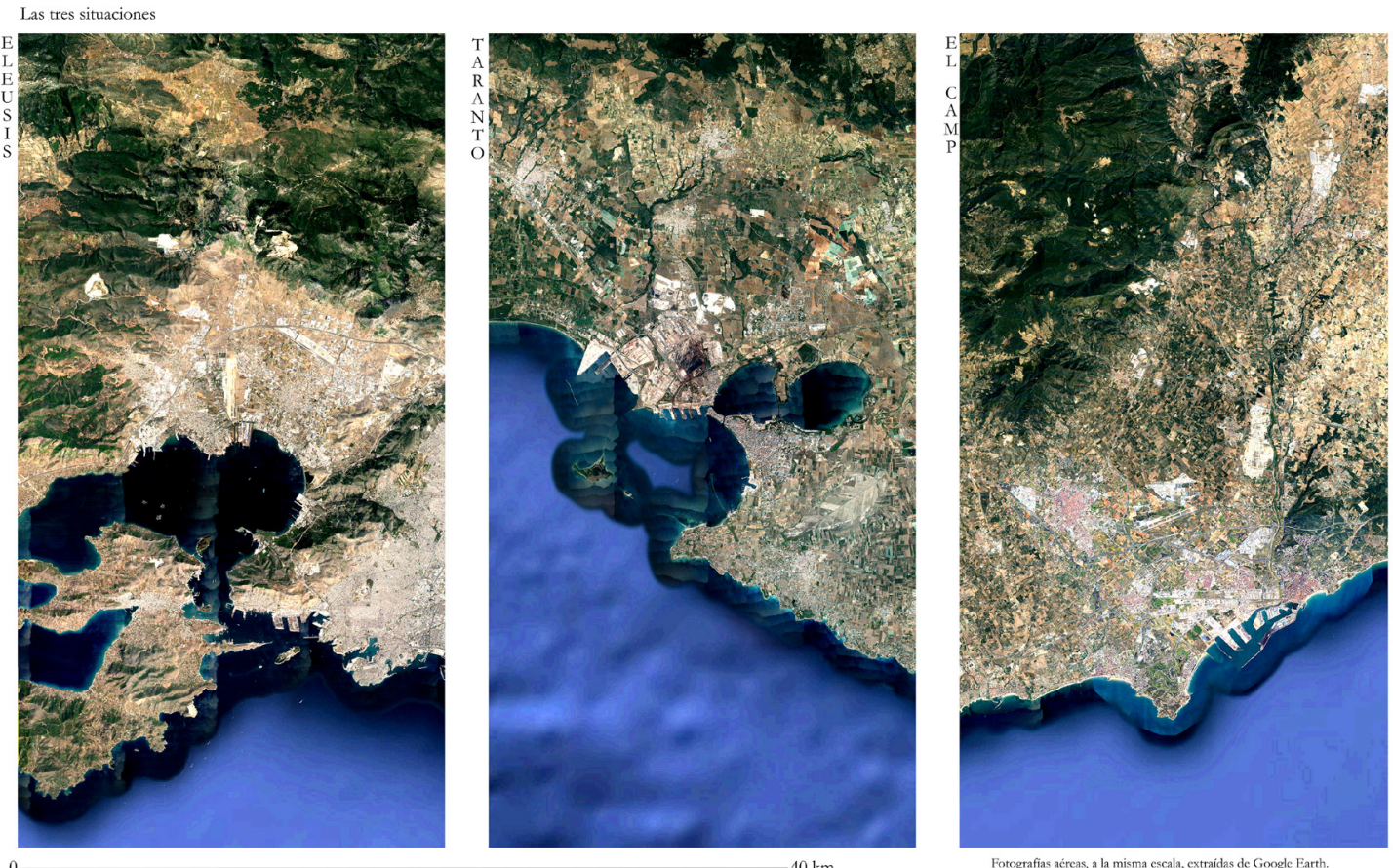

Fig. 1. Los tres casos. (Fuente: Elaboración propia en base a fotografías aéreas disponibles en Google Earth, 2019)
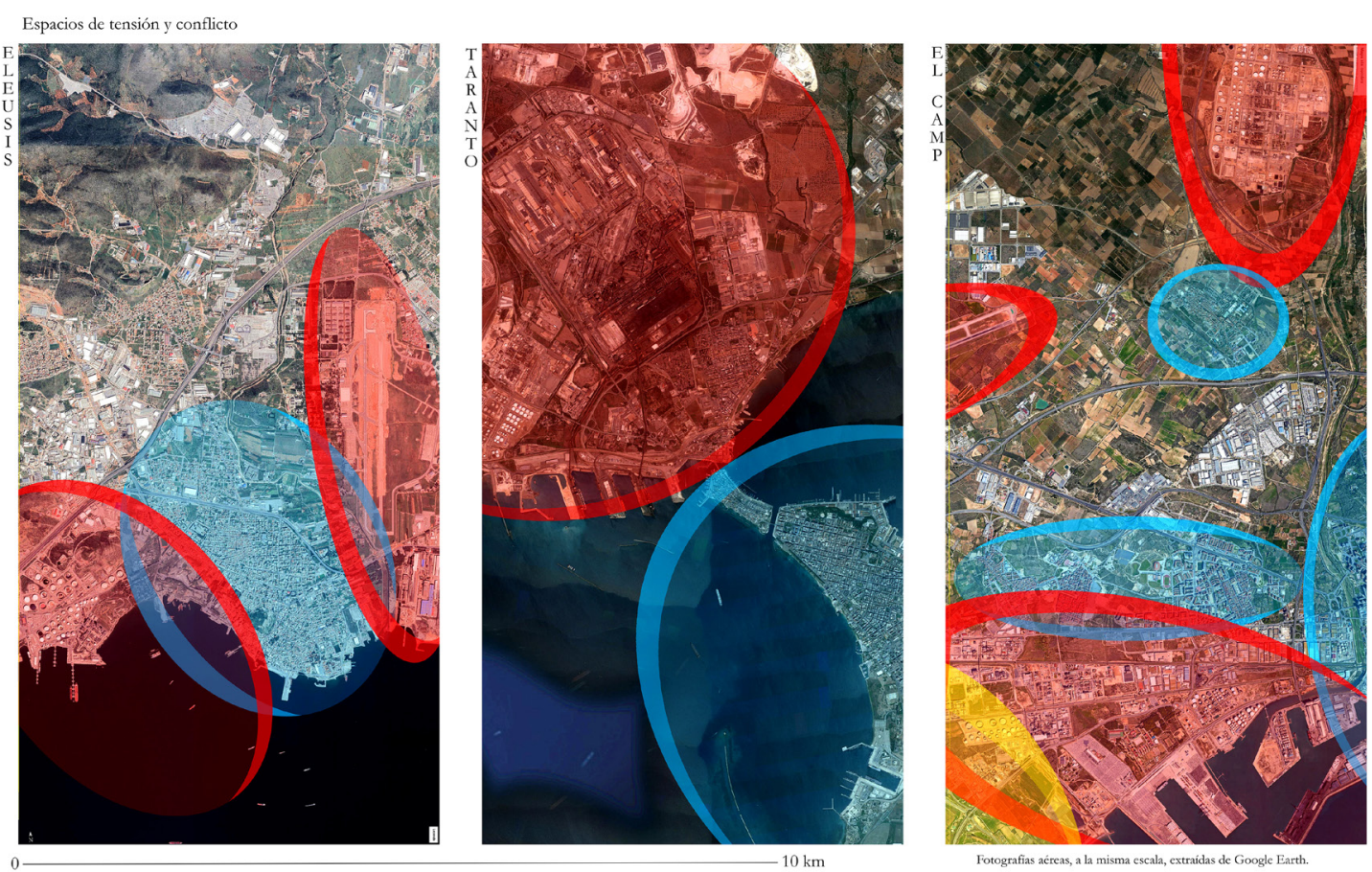

Fotografahas acteas, a ha misma escala, extraidas de Gooole Earch.

Fig. 2. Las tres situaciones. (Fuente: Elaboración propia en base a fotografías aéreas disponibles en Google Earth, 2019) 

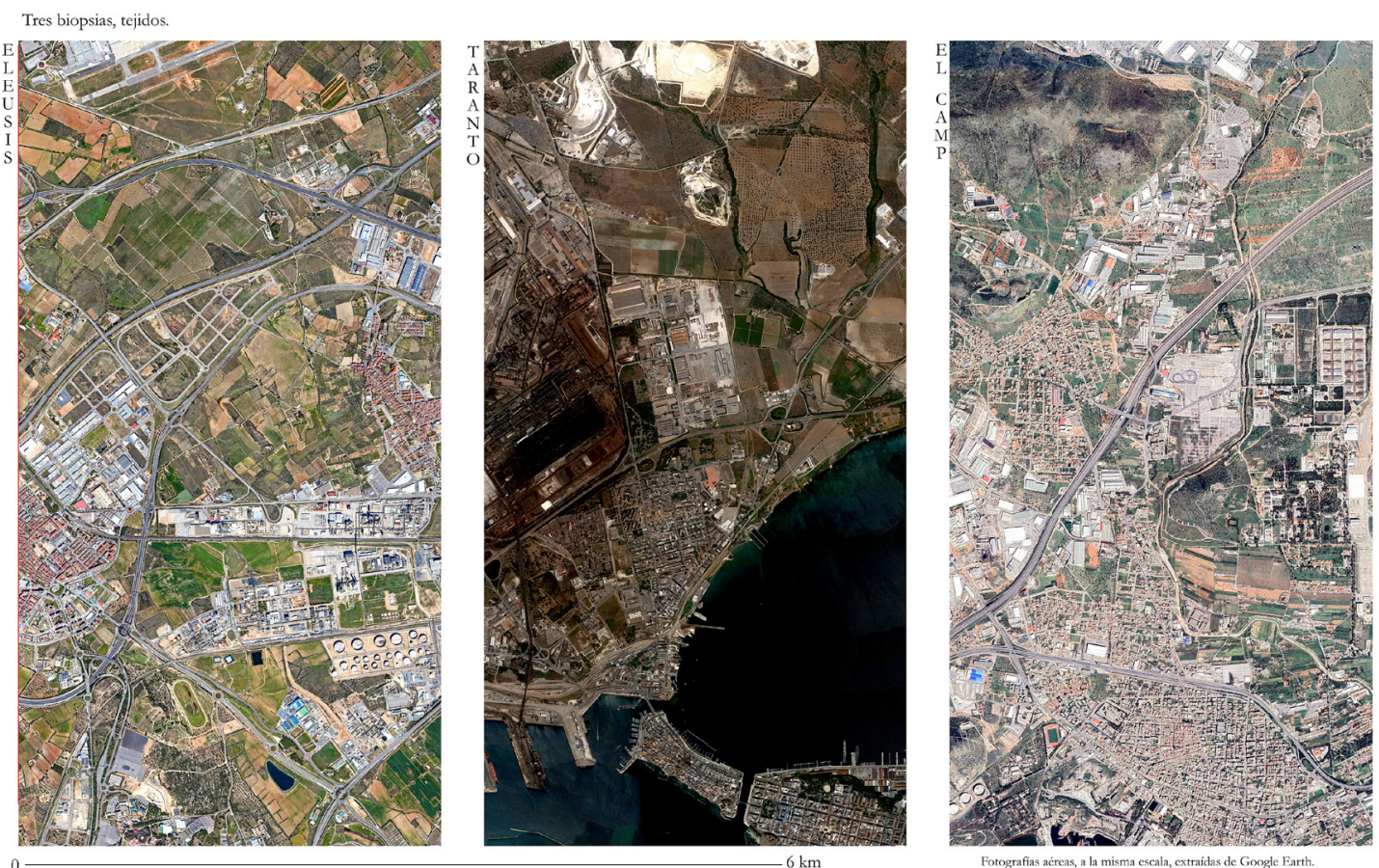

Fig. 3. Espacios de tensión y conflicto. (Fuente: Elaboración propia en base a fotografías aéreas disponibles en Google Earth, 2019)
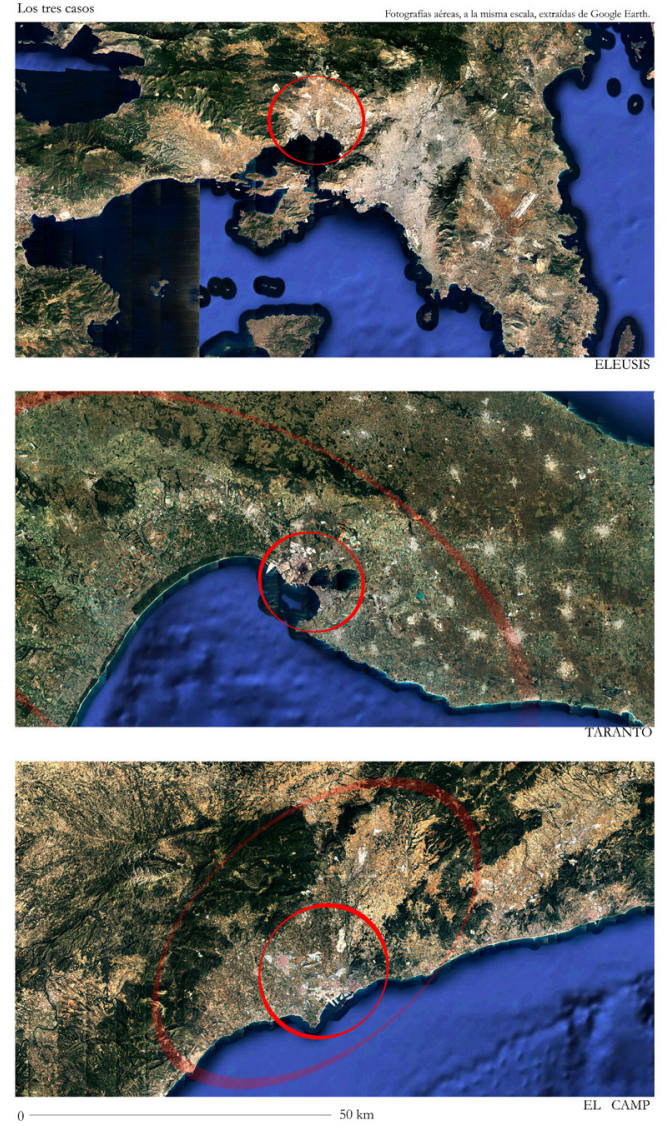

Fig. 4. Tres biopsias, tejidos. (Fuente: Elaboración propia en base a fotografías aéreas disponibles en Google Earth, 2019) 
El Turismo tiene vías claras y explícitas, pero ¿cómo llega la gran industria al Camp? El Puerto de Tarragona es el único responsable. En efecto, el Puerto es una gran infraestructura empezada a proyectar a partir de 1802 . Gracias o por su culpa, el Camp asienta hoy el mayor Complejo Petroquímico de la península con una actividad territorialmente muy diversificada. Pero mientras por el cauce del río Francolí circula hacia y desde la Refinería -situada a 10 $\mathrm{km}$ al interior del valle más petróleo que agua. El Puerto pesquero de Tarragona continúa siendo -por capturas- el mayor de Catalunya. El conflicto está servido: Turismo versus Industria Química; Producción de Energía versus ciudad -desde 1971 funciona, en el límite sur del Camp, la Central Nuclear de Vandellós. Global versus local.

Cada sector juega sus cartas. El Turismo, se ha consolidado con la construcción del Parque de Atracciones de Port Aventura World (1995). Hoy con 3.600.000 visitantes al año es el mayor de España y el sexto de Europa. Atracción que espera incrementar con un proyecto -a la espera- de nuevos casinos y hoteles con un millón de $\mathrm{m} 2$ de techo y con el consenso y beneplácito de casi todos. No hay apenas contestación ni al monocultivo turístico de algunos municipios, ni a la contaminación industrial pero sobre todo faltan estrategias de gobernanza y planeamiento comunes. El "Plan director de las actividades industriales y turísticas del Camp de Tarragona" -2003- es la única iniciativa pública consensuada, aprobada $y$ en vigencia que ha permitido delimitar - que no resolver - el conflicto. Hay pocos o nulos esfuerzos para poner sobre la mesa el conflicto sus motivos y obligadas soluciones .

\section{Conclusión}

Los tres casos de estudio comparados - Eulesis, Taranto y el Camp -nos permiten reflexiones conjuntas y muchas preguntas. Las nuevas ciudades industriales europeas, asentadas casi todas en el litoral -en el Mediterráneo especialmente- tienen como base el petróleo: su transporte, refino y el posterior uso industrial de sus derivados. Implica transporte marítimo, pantalanes, conducción de fluidos. Pero ocupan suelos de privilegio y su nueva presencia añade otras industrias afines: petroquímicas, nucleares, astilleros marítimos. Todas generan trabajo fijo especializado, pero escaso. A cambio de una enorme contaminación y riesgo. Riesgo local y beneficio foráneo -las sedes de las compañías explotadoras, nunca están dónde se asienta la industria-. Quien contamina no paga o no paga a quien debe.

Los conflictos territoriales de carácter: paisajístico, hídrico, agrícola o urbano son previsibles e inevitables. El Turismo parece incompatible con esta Ciudad Industrial tan desatenta a su medio, pero quizá podrá ser un buen contrapunto para Taranto o Eulesis, usando el mar, el Mediterráneo y su densísima historia - como el Camp ha hecho- para equilibrar la industria omnipresente. Pero también el turismo excesivo es contaminación social y cultural explícita.

¿Es posible el equilibrio? ¿Son las nuevas ciudades industriales del litoral mediterráneo, ejemplo de ciudad contemporánea compleja donde el conflicto de usos, espacios y tiempos aporta vitalidad formal y social al conjunto?

¿Cuáles deberían ser las estructuras de gobierno adecuadas para este tipo de ciudades? ¿Cuáles sus formas de organización y planeamiento? Faltan ejemplos y buenos ejemplos. Nos comprometemos a buscarlos en Castellón, Cartagena, Cádiz, La MèdeMarseille, Venezia-Marghera, Salónica, Esmirna-Alexandría... Sólo empezamos, pero estamos empeñados en ello.

\section{Agradecimientos}

Proyecto desarrollado en el marco del proyecto CHORA, subvencionado por el Ministerio de Economía, Industria y Competitividad de España. Contrato: CSO2017-82411-P.

\section{Notas}

1 El Censo de 1857 se considera el primer censo de población moderna del estado español.

2 La plataforma "Cel net" propone un trabajo conjunto de todos los agentes implicados, para buscar soluciones a las emisiones contaminantes en el Valle del Francolí y el Camp de Tarragona.

3 La Comissió dels 21 Municipis del Camp 
formada por los 21 municipios afectados por el conflicto-industria-turismo recién estrenados municipios democráticos (1979-1980) fue el único intento de organización supra municipal y posible Área Metropolitana. También un intento fallido.

4 El Plan Territorial parcial del Camp de Tarragona se aprobó en 2010 pero su desarrollo, el Plan director de l'Àmbit Central al Camp de Tarragona, nunca fue aprobado.

\section{Referencias}

Belavilas N., Saiti T., Psarioti K. .2011. «Patrimonio Industrial en Eleusis y en Triásio Pedio», Instituto Cultural del Banco Pireo

Camarda D., Rotondo F., Selicato F. 2015. Strategies for dealing with urban shrinkage: Issues and scenarios in Taranto. EUROPEAN PLANNING STUDIES, vol. 23, p. 1-21.

Corboz, André. 2001. Le territoire comme palimpseste et autres essais. Besançon : Éditions de l'imprimeur.

De Vincentiis ,P. D. L. 1878. Storia di Taranto compilata dal P. Domenico Ludovico De Vincentiis, Taranto: Tipografia Latronico,

Galanis H. 2016, «El patrimonio arquitectónico de Eleusis», Escuela de Ingenieros, Universidad de Pireo

Garnier, Tony. 1917. Une cité industrielle. Étude pour la constrution des villes. Paris : Auguste Vincent Éditeur. (1932)

Greco F., Panico A., Rotondo F. 2017. Paesaggio e rigenerazione urbana nelle città in declino demografico: tra assenza e inefficacia. Rapporto sulle città 2017. "Terzo Rapporto sulle città - Mind the gap. Il distacco tra politiche e città". Rivista online di Urban@ it - 1/2017 (ISSN 2465-2059)

Iglesies, Josep, Llobet, Salvador y Vilà, Valentí Joan. 1958. Geografia de Catalunya. Barcelona: Ed. Aedos

Lenoci S. 2005. Tra arte, ecologia e urbanistica, Roma: Meltemi.

Luisi, M., Gallo, G. T., Milella, F., Montalbano, C., Pietropaolo, L., Punzi, F. 2019. Analisi di Sistema. Le «Questioni Chiave». Rapporto per la realizzazione delle linee guida del Piano Strategico di Taranto e per la costruzione del Piano Strategico di Sviluppo e Valorizzazione del Territorio Tarantino, ASSET - Agenzia regionale Strategica per lo Sviluppo Ecosostenibile del Territorio.

Morera i Llauradó, Emili. 1901. Reseña histórica de la Comuna del Camp de Tarragona. Tarragona: Ed. Llorens Gibert i Cabré.

Oficina Técnica de Espacios Públicos. 2016-17. «Estudio de Unificación y Revalorización de areas arqueológicas y monumentos»»

Romeo S. 2019. L'acciaio in fumo, l'Ilva di Taranto dal 1945 ad oggi. Roma: Donzelli Editore.

Sardà J., Greco F., Rotondo F., 2014. Patrimonio identitario territoriale e rilancio economico: prospettive per l'agenda urbana di Taranto. In: Atti della VXII Conferenza Nazionale SIU, L'urbanistica italiana nel mondo. PLANUM, p. 589-598, Roma/Milano: Planum publisher, ISBN: 9788899237004, ISSN: 1723-0993, Milano, 15-16 maggio 2014

Vassi A. (2009), «El carácter de la costa marina de Eleusis a través de la reconsideracóon de su Plano Urbanístico», NTUA Master en Urbanismo y Territorio

Vilà, Pau. 1936. La Divisió Territorial de Catalunya. Barcelona: Ed. Seix Barral. (1977). 